Article

\title{
Isolation and Identification of Fourteen Microsatellite Markers in Clivia miniata and Clivia nobilis (Amaryllidaceae)
}

Wei Gao ${ }^{1,2,3}$, He Zhao ${ }^{3}$, Ying Liu ${ }^{3}$, Ming-Rui Li ${ }^{3}$, Eliyas Nurmamat ${ }^{4}$, Lin-Feng Li $^{3}$, Yue-Ying Ren ${ }^{1, *}$ and Hong-Xing Xiao ${ }^{3}{ }_{*}$

1 College of Traditional Chinese Medicinal Material, Jilin Agricultural University, Changchun 130118, China; E-Mail: sgaov@yahoo.com.cn

2 College of Biological Science and Technology, Changchun University, Changchun 130012, China

3 Key Laboratory of Molecular Epigenetics of Ministry of Education, Northeast Normal University, Changchun 130024, China; E-Mails: zhaoh036@nenu.edu.cn (H.Z.); liuy248@nenu.edu.cn (Y.L.); limr145@nenu.edu.cn (M.-R.L.); lilf241@nenu.edu.cn (L.-F.L.)

4 College of Chemistry and Life Sciences, Yili Normal University, Yili, 835000, China;

E-Mail: nuemmt496@nenu.edu.cn

* Authors to whom correspondence should be addressed; E-Mails: renyueying@yahoo.com.cn (Y.-Y.R.); xiaohx771@nenu.edu.cn (H.-X.X.); Tel./Fax: +86-431-8453-3086 (Y.-Y.R.); +86-431-8259-9216 (H.-X.X.).

Received: 2 May 2012; in revised form: 18 July 2012 / Accepted: 25 July 2012 /

Published: 2 August 2012

\begin{abstract}
Clivia is a genus of great horticultural importance and has been widely cultivated as ornamental plants in all over the world. In order to assess the phylogenetic relationships and genetic diversity of the wild Clivia species and cultivars, we isolated AC-enriched repeats using FIASCO from a single clone each of $C$. miniata Regel. and Clivia nobilis Lindl. Of the fourteen repeats, 10 were polymorphic and 4 were monomorphic. The polymorphic marker loci were characterized using 61 Clivia accessions. The number of alleles ranged from two to six, observed heterozygosity ranged from 0.04 to 1.00 and expected heterozygosity ranged from 0.04 to 0.83 . These microsatellite marker loci provide tools for future studies of Clivia species and cultivars.
\end{abstract}

Keywords: Clivia miniata; Clivia nobilis; genetics diversity; microsatellite 


\section{Introduction}

The genus Clivia Lindl. belongs to the family Amaryllidaceae and includes six diploid species $(2 n=2 x=22)$ primarily distributed in southern Africa [1-3]. Clivia, an evergreen genus with rhizomes, prefers well-drained, semi-shade and shaded habitats [4-6]. As one of the famous ornamentals with colorful flower and tremendous economic values, the species within Clivia have been cultivated in many parts of the world and lots of cultivars have been developed in the past decades [5,7]. To gain a better understanding of the phylogenetic relationships within the genus Clivia, several previous studies have constructed the phylogenies of Clivia using RAPD markers and DNA sequences [7-9]. The results of these studies provide us fundamental insight into the systematic relationships among the six congeneric species. Nevertheless, these wild Clivia species were usually used as genetic resources for the interspecific cross-breeding [5,10-12]. Therefore, the phylogenetic relationships and genetic erosion of these wild Clivia species and cultivars remain unclear due to the lack of reliable and efficient genetic and molecular markers. To obtain the genetic composition of the wild Clivia species and cultivars, we isolated and identified fourteen genomic microsatellites from the species Clivia miniata Regel. and Clivia nobilis Lindl. These microsatellite primers provide us a valuable resource to evaluate the phylogenetic relationships and genetic diversity of wild Clivia species and cultivars.

\section{Results and Discussion}

A total of 68 positive clones for C. miniata and 14 for $C$. nobilis were sequenced, of which 33 clones of them (26 from C. miniata and seven from C. nobilis) containing enough flanking regions (>30 base pair) were successfully designed primer. Eleven microsatellites from C. miniata (CM3, CM9, CM12, CM54, CM65, CM103, CM137, CM253, CM289, CM357 and CM425) and three from C. nobilis (CN68, CN89 and CN106) producing clear amplicons of the expected size were selected for the following experiment, and the other primer pairs which amplified multi-bands were abandoned in this study. The band size is scored against a 25 base pair DNA marker (Takara). Finally, four of these primer pairs were monomorphic (GenBank numbers: JQ782264, JQ782270, JQ782274 and JQ782277), and the other 10 polymorphic loci produced a total of thirty-five alleles, with an average of 3.5 alleles per locus. The number of alleles per locus $\left(N_{\mathrm{A}}\right)$ was two to six, and the observed heterozygosity $\left(H_{\mathrm{O}}\right)$ and expected heterozygosity $\left(H_{\mathrm{E}}\right)$ varied from 0.04 to 1.00 and from 0.04 to 0.83 , respectively (Table 1). No significant linkage disequilibrium was detected for any pair of loci.

Table 1. Results of initial primer screening in Clivia miniata, Clivia nobilis and hybrids of the two species. Parameters shown for each pair of primers are the number of the samples $(N)$, number of alleles $\left(N_{\mathrm{A}}\right)$, observed heterozygosity $\left(H_{\mathrm{O}}\right)$ and expected heterozygosity $\left(H_{\mathrm{E}}\right)$.

\begin{tabular}{|c|c|c|c|c|c|c|c|c|c|}
\hline \multirow[b]{2}{*}{ Locus } & \multicolumn{3}{|c|}{ Clivia miniata $(N=51)$} & \multicolumn{3}{|c|}{ Hybrid $(N=2)$} & \multicolumn{3}{|c|}{ Clivia nobilis $(N=8)$} \\
\hline & $N_{\mathrm{A}}$ & $\boldsymbol{H}_{\mathrm{E}}$ & $\boldsymbol{H}_{\mathbf{O}}$ & $N_{\mathrm{A}}$ & $\boldsymbol{H}_{\mathrm{E}}$ & $H_{\mathbf{O}}$ & $N_{\mathrm{A}}$ & $\boldsymbol{H}_{\mathrm{E}}$ & $H_{\mathbf{O}}$ \\
\hline CM9 & 3 & 0.17 & 0.18 & 1 & 0.00 & 0.00 & 1 & 0.00 & 0.00 \\
\hline CM12 & 4 & 0.22 & 0.18 & 3 & 0.83 & 0.50 & 3 & 0.49 & 0.38 \\
\hline CM54 & 1 & 0.00 & 0.00 & 1 & 0.00 & 0.00 & 2 & 0.22 & 0.00 \\
\hline CM65 & 2 & 0.09 & 0.10 & 1 & 0.00 & 0.00 & 1 & 0.00 & 0.00 \\
\hline
\end{tabular}


Table 1. Cont.

\begin{tabular}{|c|c|c|c|c|c|c|c|c|c|}
\hline \multirow[b]{2}{*}{ Locus } & \multicolumn{3}{|c|}{ Clivia miniata $(N=51)$} & \multicolumn{3}{|c|}{ Hybrid $(N=2)$} & \multicolumn{3}{|c|}{ Clivia nobilis $(N=8)$} \\
\hline & $N_{\mathrm{A}}$ & $H_{\mathrm{E}}$ & $H_{O}$ & $N_{\mathrm{A}}$ & $\boldsymbol{H}_{\mathrm{E}}$ & $H_{\mathbf{O}}$ & $N_{\mathrm{A}}$ & $\boldsymbol{H}_{\mathrm{E}}$ & $H_{O}$ \\
\hline CM103 & 4 & 0.48 & 0.53 & 2 & 0.50 & 0.50 & 1 & 0.00 & 0.00 \\
\hline CM137 & 2 & 0.04 & 0.04 & 1 & 0.00 & 0.00 & 1 & 0.00 & 0.00 \\
\hline CM289 & 3 & 0.44 & 0.65 & 2 & 0.50 & 0.50 & 4 & 0.42 & 0.38 \\
\hline CM357 & 5 & 0.56 & 0.76 & 3 & 0.83 & 0.83 & 2 & 0.20 & 0.00 \\
\hline CN68 & 4 & 0.23 & 0.16 & 1 & 0.00 & 0.00 & 3 & 0.30 & 0.00 \\
\hline CN106 & 2 & 0.50 & 1.00 & 2 & 0.67 & 1.00 & 2 & 0.47 & 0.88 \\
\hline
\end{tabular}

\section{Experimental Section}

\subsection{Isolation of Microsatellite Markers}

The samples for this study were collected from fifty-one cultivars of C. miniata, eight wild individuals of $C$. nobilis and two hybrids between the two species. The microsatellite-enriched libraries were constructed following the procedure of Fast Isolation by AFLP of Sequences Containing repeats (FIASCO) [13]. In brief, total genomic DNA was extracted from a single individual each of C. nobilis and C. miniata. About $300 \mathrm{ng}$ genomic DNA for each species was completely digested with MseI separately (New England BioLabs, Beverly, MA, USA). Then, these digested products were ligated to the MseI adaptor pair (5'-TACTCAGGACTCAT-3'/5'-GACGATGAGTCCTGAG-3') [14]. The diluted digestion-ligation mixture $(1: 10)$ was then amplified with MseI-N primer (5'-GATGAGTCCTGAGTAAN-3') using the following cycle conditions: $95{ }^{\circ} \mathrm{C}$ for $5 \mathrm{~min}, 20$ cycles of $94{ }^{\circ} \mathrm{C}$ for $30 \mathrm{~s}, 53{ }^{\circ} \mathrm{C}$ for $1 \mathrm{~min}, 72{ }^{\circ} \mathrm{C}$ for $1 \mathrm{~min}$, and a finally extension at $72{ }^{\circ} \mathrm{C}$ for $5 \mathrm{~min}$.

For enrichment, these PCR products were denatured and hybridized with biotin-labeled (AC) 15 probes, and then these DNA fragments were captured by streptavidin-coated magnetic beads (Promega, Madison, WI, USA). These enrichment products were purified with a Gel Extraction Kit (Takara, Liaoning, China) and ligated into the pMD18 vector (Takara) and transformed into E. coli strain JM109 (Takara). The positive clones were identified by PCR amplification using (AC) $)_{10}$ and $\mathrm{M}_{13+} / \mathrm{M}_{13-}$ primers, respectively. If one of the primer combinations was successfully amplified, it suggested that the amplicons contained microsatellite motifs. The positive clones for C. miniata and C. nobilis were sequenced on an ABI 3730 DNA analyzer (Applied Biosystems, Foster City, CA, USA) using M13F as sequencing primer. Primers were designed according to Li et al. [15]: 1. the length of primer was $18-25 \mathrm{bp} ; 2$. annealing temperature was $55-65{ }^{\circ} \mathrm{C} ; 3$. GC content of primer was $40-60 \%$.

\subsection{Detection of Polymorphism and Data Analysis}

Primer pairs were used to amplify DNA of 61 individuals. PCR amplifications were performed in a total volume of $20 \mu \mathrm{L}$ containing the following components: $50 \mathrm{ng}$ of DNA template, $0.2 \mu \mathrm{M}$ of each dNTP $(10 \mathrm{mM}), 0.5 \mathrm{pmol}$ of each primer, $1 \times$ PCR buffer (containing $2.5 \mathrm{mM} \mathrm{Mg}^{2+}$ ) and $1 \mathrm{U}$ of high-fidelity Taq polymerase (Takara). The PCR reactions were performed on an ABI 2720 thermocycler: an initial denaturation of $5 \mathrm{~min}$ at $95{ }^{\circ} \mathrm{C}, 35$ cycles of $30 \mathrm{~s}$ at $94{ }^{\circ} \mathrm{C}$, annealing 
temperature (Ta) for $30 \mathrm{~s}$ (Ta for each primer pairs were listed in Table 2), $30 \mathrm{~s}$ at $72{ }^{\circ} \mathrm{C}$, and a final extension of $72{ }^{\circ} \mathrm{C}$ for $8 \mathrm{~min}$. These amplification products were resolved on $6 \%$ polyacrylamide denaturing gel electrophoresis and visualized using silver staining. To discriminate the real alleles from Taq polymerase errors and nonspecific amplification products, only clear bands with expected size were considered and the rare alleles (only occured once) were removed from the dataset.

Table 2. Characteristics of ten microsatellite markers based on 61 Clivia accessions. For each locus, the names, primer sequences [forward $(F)$ and reverse $(R)$ ], repeat motif, size of the cloned allele, annealing temperature, number of alleles and GenBank accession number are shown.

\begin{tabular}{|c|c|c|c|c|c|c|}
\hline Locus & Primer sequences $\left(5^{\prime}-3^{\prime}\right)$ & Repeat & $\begin{array}{l}\text { Size } \\
\text { (bp) }\end{array}$ & $T_{\mathrm{a}}$ & $N_{\mathrm{A}}$ & GenBank \\
\hline \multirow[t]{2}{*}{ CM9 } & F: TTACCТCCТCCAАCTCACAG & $(\mathrm{TG})_{9}$ & 251 & 48 & 3 & JQ782265 \\
\hline & R: ATGAAAACGGCCCGAATTAC & & & & & \\
\hline \multirow[t]{2}{*}{ CM12 } & F: CAACCTCAAGCTCAGTCTCA & $(\mathrm{AC})_{6} \mathrm{~T}(\mathrm{AC})_{2}$ & 230 & 47 & 4 & JQ782266 \\
\hline & R: AGGTGCAGGATGATAATGGT & & & & & \\
\hline \multirow[t]{2}{*}{ CM54 } & F: GAGCAACTCAGGAAGGGATG & $(\mathrm{GT})_{16}$ & 194 & 46 & 2 & JQ782267 \\
\hline & R: CCGCTAAGGACTTTACGCAC & & & & & \\
\hline \multirow[t]{2}{*}{ CM65 } & F: AGGGTGAGAGTGTAGGTGTG & $(\mathrm{GT})_{4} \mathrm{~T}(\mathrm{TG})_{4}$ & 190 & 48 & 2 & JQ782268 \\
\hline & R: CTTAGGCATGTATAGTGGCC & & & & & \\
\hline \multirow[t]{2}{*}{ CM103 } & F: ACCCCTTACACAGACTACCA & $(\mathrm{AC})_{15} \mathrm{G}(\mathrm{CA})_{21}$ & 313 & 47 & 4 & JQ782271 \\
\hline & R: GATGGGTAGAAGGTGGTTGT & & & & & \\
\hline \multirow[t]{2}{*}{ CM137 } & F: TTCTTGCCGACAATCCCGTA & $(\mathrm{AC})_{6}$ & 288 & 47 & 2 & JQ782273 \\
\hline & R: TGATGGTCGCAAAATTCACG & & & & & \\
\hline \multirow[t]{2}{*}{ CM289 } & F: GGATATTATGTTGCCAAGCC & $(\mathrm{TG})_{11}$ & 207 & 58 & 5 & JQ782275 \\
\hline & R: AAAGTTGAATCGCGGTCCCA & & & & & \\
\hline \multirow[t]{2}{*}{ CM357 } & F: GCGAATGATAATCGTGAACC & $(\mathrm{GT})_{16}$ & 160 & 46 & 6 & JQ782276 \\
\hline & R: TCСТCСТTTTCTCACACTTC & & & & & \\
\hline \multirow[t]{2}{*}{ CN68 } & F: TTCTGACTTACACCTACACA & $(\mathrm{AC})_{17}$ & 167 & 47 & 5 & JQ782269 \\
\hline & R: ATTATGCACTTGGATCTAGG & & & & & \\
\hline \multirow[t]{2}{*}{ CN106 } & F: AACAGCAGGAAATTAGGGAG & $(\mathrm{TG})_{16}$ & 195 & 48 & 2 & JQ782272 \\
\hline & R: TCACAAGCATACACACACAC & & & & & \\
\hline
\end{tabular}

The preliminary population genetic analyses for these microsatellite loci were performed using the software GENEPOP with the default settings and assumptions [16], including the number of alleles per locus $\left(N_{\mathrm{A}}\right)$, observed heterozygosity $\left(H_{\mathrm{O}}\right)$, expected heterozygosity $\left(H_{\mathrm{E}}\right)$ and linkage disequilibrium $(\mathrm{LD})$.

\section{Conclusions}

In this study, fourteen microsatellite markers were isolated and identified from the species C. miniata and C. nobilis. Ten polymorphic microsatellite markers may be useful in future studies of conservation biology and population genetics of the wild Clivia species and cultivars. 


\section{Acknowledgments}

We are grateful to anonymous reviewers for constructive suggestions to improve this manuscript. This work was finance supported by the Programme for Introducing Talents to Universities (B07017),

National Natural Science Foundation of China (31100157 and 31170429) and Fundamental Research Funds for the Central Universities (10QNJJ011).

\section{References}

1. Rourke, J.P. Clivia mirabilis (Amaryllidaceae: Haemantheae) a new species from Northern Cape, South Africa. Bothalia 2002, 32, 1-7.

2. Murray, B.G.; Ran, Y.E.; Lange, P.D.; Hammett, K.R.W.; Truter, J.T.; Swanevelder, Z.H. A new species of Clivia (Amaryllidaceae) endemic to the Pondoland Centre of Endemism, South Africa. Bot. J. Linn. Soc. 2004, 146, 369-374.

3. Murray, B.G.; Wong, C.; Hammet, K.R.W. The karyotype of Clivia mirabilis analyzed by differential banding and fluorescence in-situ hybridization. Plant Syst. Evol. 2011, 293, 193-196.

4. Duncan, G.; Du Plessis, N.M.; Bodley, E. Bulbous Plants of Southern Africa, a Guide to Their Cultivation and Propagation; Tafelberg Publishers: Cape Town, South Africa, 1989.

5. Duncan, G.D. Grow Clivia; The National Botanical Institute: Cape Town, South Africa, 1999.

6. Swanevelder, Z.H. Diversity and Population Structure of Clivia miniata Lindl. (Amaryllidaceae): Evidence from Molecular Genetics and Ecology; M.S. Thesis, University of Pretoria: Pretoria, South Africa, 2003.

7. Ran, Y.; Hammett, K.R.W.; Murray, B.G. Phylogenetic analysis and karyotype evolution in the genus Clivia (Amaryllidaceae). Ann. Bot. 2001, 87, 823-830.

8. Ran, Y.; Murray, B.G.; Hammett, K.R.W. Evaluating genetic relationships between and within Clivia species using RAPDs. Sci. Hortic. 2001, 90, 167-179.

9. Conrad, F. Molecular Systematic, Biogeography and Dating of the Tribe Haemantheae (Amaryllidaceae) and the Phylogeography of Clivia. Ph.D. Dissertation, University of Cape Town, Cape Town, South Africa, December 2008.

10. Walters, K. Clivias. Herbertia 1971, 44, 29-32.

11. McNeil, P.G. Hybridising Clivia. Herbertia 1985, 41, 24-29.

12. Ran, Y.; Hammett, K.R.W.; Murray, B.G. Hybrid identification in Clivia (Amaryllidaceae) using Chromosome Banding and Genomic. Ann. Bot. 2001, 87, 457-462.

13. Zane, L.; Bargelloni, L.; Patarnello, T. Strategies for microsatellite isolation: A review. Mol. Ecol. 2002, 11, 1-16.

14. Vos, P.; Hogers, R.; Bleeker, M.; Reijans, M.; Lee, T.; Hornes, M.; Frijters, A.; Pot, H.; Peleman, J.; Kuiper, M.; Zabeau, M. AFLP: A new technique for DNA fingerprinting. Nucleic. Acids Res. 1995, 23, 4407-4414.

15. Li, L.F.; Pang, D.; Liao, Q.L.; Xiao, H.X. Genomic and EST microsatellite markers for Aquilegia flabellata and cross-amplification in A. oxysepala (Ranunculaceae). Am. J. Bot. 2011, 98, e213-e215. 
16. Raymond, M.; Rousset, F. GENEPOP (version 1.2): Population genetics software for exact tests and ecumenicism. J. Hered. 1995, 86, 248-249.

(C) 2012 by the authors; licensee MDPI, Basel, Switzerland. This article is an open access article distributed under the terms and conditions of the Creative Commons Attribution license (http://creativecommons.org/licenses/by/3.0/). 